\title{
Validação experimental de AMH como marcador quantitativo da reserva folicular ovariana utilizando ovariectomia unilateral em éguas
}

Renata Cristina Uliani[a]* ${ }^{*}$,Alan James Conley ${ }^{[b]}$, Cynthia J Corbin ${ }^{[b]}$,Aimé de Medeiros Friso ${ }^{[a]}$, Luciana FS Maciel[ ${ }^{[a]}$, Marco Antonio Alvarenga $a^{[a]}$

\footnotetext{
[a] Departamento de Reprodução Animal, Faculdade de Medicina Veterinária e Zootecnia, Universidade Estadual Paulista (UNESP), Botucatu, SP, Brasil

[b] Department of Population Health and Reproduction, School of Veterinary Medicine, University of California Davis, Davis, CA, Estados Unidos
}

${ }^{*}$ Autor correspondente

e-mail: renata.uliani@gmail.com

\section{Resumo}

As estimativas da reserva ovariana têm sido procuradas há muito tempo como possíveis preditores de fertilidade. Os hormônios foliculares ovarianos são obviamente candidatos, mas a maioria está sob controle regulatório de feedback e normalizados apesar da diminuição do número de folículos ovarianos sob influência de suporte gonadotrópico positivo. No entanto, o hormônio anti-Mülleriano (AMH) tem sido utilizado como marcador da reserva folicular ovariana nas mulheres. Para nosso conhecimento, a reserva folicular ovariana não foi manipulada experimentalmente com o objetivo de investigar os efeitos nas concentrações de AMH, certamente não em cavalos. Portanto, a hemiovariectomia foi utilizada para reduzir pela metade a reserva folicular ovariana e as concentrações de AMH foram monitoradas antes e durante duas semanas após a cirurgia. Quatorze éguas de várias raças foram hemiovariectomizadas durante a época de reprodução sob anestesia local via laparotomia de flanco. As éguas foram divididas por faixa etária, sendo jovens ( $\mathrm{n}=6$, média $6,0 \pm 0,9$ yrs) e velhas ( $n=8 ; 18,4 \pm 0,7$ yrs). A incisão foi fechada em duas camadas utilizando uma linha de sutura contínua, incluindo as camadas musculares abdominais, seguidas de aproximação do tecido subcutâneo e sutura da pele. 0 soro foi recolhido de todas as éguas no dia anterior à cirurgia e diariamente durante 15 dias após a cirurgia. O AMH foi mensurado utilizando um kit ELISA comercial de acordo com as instruções do fabricante (Equine AMH ELISA, Ansh Labs, Webster, TX, EUA). 0 valor médio de AMH antes da cirurgia foi de $1,0 \pm 0,1 \mathrm{ng} / \mathrm{mL}$ e não diferiu por idade $(1,0 \pm 0,1$ e 1,0 $\pm 0,2 \mathrm{ng} / \mathrm{mL}$, respectivamente em éguas jovens e velhas) - as concentrações de AMH diminuíram progressivamente, atingindo 0,4 \pm 0,1 ng / mL 5 dias após a cirurgia, 54,5\% das concentrações pré-cirúrgicas - permanecendo constante nos dias que seguiram. 
Os dados mostram que, apesar da inevitável e progressiva perda da reserva folicular ovariana entre os 6 e os 18 anos de idade, isso não refletiu em diminuição nas concentrações de AMH. Entretanto, a diminuição significativa da reserva folicular ovariana por hemiovariectomia cirúrgica foi seguida por uma queda da AMH para metade das concentrações pré-cirúrgicas. Concluímos que a AMH é um indicador quantitativo agudo da reserva folicular ovariana após hemiovariectomia, porém, com o lento declínio progressivo das populações de folículos primordiais que inevitavelmente acompanha o envelhecimento, a compensação dos ovários e a reposição contínua das populações de folículos antrais atrapalham este declínio em éguas até quase 20 anos de idade. Portanto, deve-se ter cautela na interpretação das concentrações de AMH como marcador de fertilidade em éguas com menos de 20 anos de idade.

Palavras-chave: Hormônio Anti-Mülleriano. Éguas. Ovariectomia. 